\title{
MARY DASCOMB: UMA BREVE ANÁLISE DE SUA TRAJETÓRIA
}

Jamilly Nicácio Nicolete

Centro Universitário Toledo - UNITOLEDO, Departamento de Educação, Araçatuba, SP. E-mail: jamillynicacio@hotmail.com.

\section{RESUMO}

O presente trabalho analisa a inserção da educadora norte-americana Mary Parker Dascomb em terras brasileiras e sua participação na História da Educação, bem como sua influência na composição de uma educação moderna e progressista - como muitos pensavam - defendendo ideais almejados pelos republicanos e grupos sociais interessados na transformação da sociedade brasileira nesse momento histórico. Através da análise de cartas trocadas entre Mary e Horace Lane, também educador e diretor da Escola Americana de São Paulo, hoje, Mackenzie. As cartas versavam sobre seu trabalho, de relações hoje negadas pela instituição, como com a maçonaria e de diversos espaços por onde Dascomb circulou por ser uma mulher letrada, norte-americana e solteira. Sua inuptividade garantiu-lhe acesso a diversos espaços fechados para as mulheres que se mantinham em um matrimônio. Sem contar, que o fato de ser uma mulher solteira era considerada pela missão presbiteriana, como uma vantagem econômica, como veremos.

Palavras-chave: Mary Dascomb, presbiterianismo, educação, cartas, Escola Americana.

\section{MARY DASCOMB: A BRIEF ANALYSIS OF HER TRAJECTORY}

\begin{abstract}
The present work analyzes the insertion of the North American educator Mary Parker Dascomb in Brazilian lands and its participation in the History of Education, as well as its influence in the composition of a modern and progressive education - as many thought - defending ideals desired by Republicans and social groups Interested in the transformation of Brazilian society in this historical moment. Through the analysis of letters exchanged between Mary and Horace Lane, also educator and director of the American School of St. Paul, today, Mackenzie. The letters spoke of her work, of relations denied by the institution today, as with Freemasonry and of various spaces through which Dascomb circulated for being a literate, American and single woman. His impenitence guaranteed him access to several enclosed spaces for those who were in a marriage. Not to mention, that being a single woman was considered by the Presbyterian mission as an economic advantage, as we shall see.
\end{abstract}

Keywords: Mary Dascomb, Presbyterianism, Education, Letters, American School. 


\section{INTRODUÇÃO}

O presente trabalho contempla a trajetória da norte-americana Mary Dascomb (18421917), primeira missionária educadora enviada ao Brasil pela Junta de Missões Estrangeiras de Nova York. Buscamos fazê-lo sob a perspectiva crítica de Pierre Bourdieu (1996), que recusa a possibilidade de se construir uma trajetória como um caminho de sequências ordenadas. Esse teórico ressalta que, diante das multifacetadas características que marcam os sujeitos históricos, as narrativas de vida que insistem em construir um "sentido de existência", significados, linearidade, coerência, tratam-se apenas de tentativas de unificação de um "eu", não passando de representações sobre a vida, ao que ele nomeia de "ilusão biográfica".

As missivas contém uma intimidade que possibilita uma ressignificação das representações sobre diversos acontecimentos do período estudado, o final do século XIX e início do século XX. Estes documentos trazem embutido o descomprometimento com a esfera pública, podendo, assim, serem mais minuciosos e descritivos que os documentos ditos oficiais. As cartas escritas por Mary Dascomb, disponíveis nos Anais do Museu Paulista, estão divididas em dois períodos, o primeiro é mais longo, vai de 1886 a 1907 e contém 90 correspondências, e o segundo, de 1908 a 1912, um período de apenas quatro anos, mas que apresenta um volume de cartas maior, 103.

As cartas, escritas com frequência desde o início, tornaram-se semanais, e com o passar dos anos, tinham uma sequência de conversas e respostas registradas entre 2 e 3 dias. Mary anotava, muitas vezes, o local de onde escrevia, apenas "Curityba", ou "Eschola de Curityba", mas também escreveu a Lane enquanto trabalhava no interior de São Paulo e durante as viagens que fez aos Estados Unidos. Detalhes como o horário e o tempo de escrita também aparecem muitas vezes.

O objetivo deste trabalho foi compreender, nas missivas, os relatos acerca da rotina da escola, informações privilegiadas sobre a igreja, detalhes de sua vida pessoal, os diversos personagens da história da Igreja Presbiteriana do Brasil, com quem Mary viveu, conviveu, os acontecimentos políticos, as transformações econômicas e sociais, daqui e de seu país de origem. A missionária e educadora também escreve sobre suas leituras, fala de seus (des) contentamentos, viagens, das chegadas e partidas dos professores, da dificuldade em conseguilos, do trabalho realizado pela escola, fala dos alunos, e muitos outros temas.

\section{METODOLOGIA}

Entre Mary Dascomb e Horace Lane, havia uma rede de sociabilidade que passava pela igreja presbiteriana enquanto instituição, pelas escolas americanas, a missão, os missionários amigos em comum, familiares. As questões que se podem colocar a esse tipo de documentação nos mostraram a preocupação de Mary em parecer sempre ocupada, ativa - apesar de algumas contradições - se dizia otimista, positiva e, se esteve andando por caminhos maus, a culpa era de sua companhia.

Malatian (2009) aponta a importância de definir qual a questão a ser colocada ao documento para que ele nos fale algo. Ao analisar a correspondência como objeto, o pesquisador levará em conta seu caráter altamente subjetivo e, mais do que nunca a veracidade dos fatos, irá buscar, nesses documentos, a expressão e a contenção do eu, em seus diversos papéis sociais, em termos de sentimentos, vivências e práticas culturais. Ao utilizá-la como fonte se deverá ter em mente que as informações nelas contidas serão sempre versões individuais ou coletivamente construídas sobre determinados acontecimentos vividos pelo narrador ou dos quais se inteirou de diversas formas como conversas, relatos, leituras. As cartas podem ainda ser confrontadas com outros documentos.

Peter Gay (1999) assinala que as cartas, ao contarem "realidades interiores" reproduzem experiências individuais nas quais fantasias e "realidades" se mesclam num jogo de ocultar/ revelar apresentado como compromisso com a verdade. 
Na perspectiva de Malatian (2009), ao analisar o processo de elaboração do documento, algumas correspondências podem ser classificadas como cartas de família: a motivação de sua escrita, as condições de sua produção, sua circulação e recepção. É possível analisar as cartas procurando nelas o habitus que rege conteúdos e práticas. Constituem referentes que conduzem as correspondências segundo geração, sexo ou situação econômica. O direito a uma escrita pessoal não se estabelece sem conflitos, por isso as estratégias de escrita por meio de códigos, símbolos - as cartas de Mary Dascomb foram escritas em inglês. Do ponto de vista cultural, será possível descobrir os apelos a data, hora, ritmo epistolar, tempo gasto na escrita, momento da chegada ou partida do correio. Que a missivista, muitas vezes, como dissemos, também registrou.

\section{RESULTADOS}

A vinda de mulheres como Mary Dascomb, contribuiu para mover o processo histórico e transformar hábitos culturais demasiadamente arraigados na consciência individual e coletiva oitocentista, à medida que esta educadora, agindo e re-agindo na relação de interdependência como ser social, contribuiu para ampliar ou afrouxar o habitus ${ }^{1}$. A educação civilizadora da mulher foi um caminho que se abriu para que a mesma pudesse transitar por espaços privados e públicos, porém ainda com muitos limites.

O período em que Mary Parker Dascomb atuou como missionária, professora e gestora da obra educacional presbiteriana no Brasil, 1869-1917, foi marcado por transformações políticas, sociais, econômicas e educacionais. Essas mudanças passavam pelo fim da monarquia, o fim do trabalho escravo e o início do trabalho livre e assalariado, participação do capital estrangeiro, tanto inglês como norte-americano, as imigrações e a intensa circulação de novas tendências de pensamento: positivismo, industrialismo, ruralismo (HILSDORF, 2003).

Tais transformações representavam para a elite a ideia de progresso e modernidade. Segundo Moraes (1994), essa mentalidade influenciou também o imaginário das populações rurais. Elas entendiam que as cidades representavam a possibilidade de uma série de conquistas: trabalho regular e remunerado, acesso rápido ao dinheiro e às mercadorias, uma vida cotidiana mais agitada e com mais atrativos, acesso à educação e à informação. Porém, o processo de crescimento urbano foi marcado pelas contradições e problemas sofridos pela camada populacional mais pobre: falta de moradia, problemas com o abastecimento de alimentos e água, epidemias, subemprego e desemprego. Violência e mendicância também foram alguns dos problemas produzidos no contexto urbano. Nem todos usufruíam plenamente dos avanços e benefícios da vida urbana; apenas a camada mais rica tinha oportunidades nos bairros de elite e no centro comercial.

No XX The Woman's Foreign Missionary Society of the Presbyterian Church, de 1890, as mudanças no cenário político aparecem como positivas para o trabalho presbiteriano:

Desde o nosso último relatório o império do Brasil tornou-se uma república. Esta revolução sem derramamento de sangue não era de todo inesperada, ela simplesmente antecipou os planos futuros das classes dominantes, foi "o fruto maduro sacudido um pouco mais cedo do que teria caído sozinho." Esta mudança no governo abre um caminho glorioso para as Igrejas protestantes. Com a separação entre Igreja e Estado e a liberdade religiosa assegurada, vêm grandes responsabilidades e oportunidades para o povo de Deus. Este campo é nosso para possuí-lo e avançar, como nunca antes, a causa e o reino de Deus.

\footnotetext{
${ }^{1}$ A partir de Bourdieu (2007).
} 


\section{DISCUSSÃO}

Blackford (1867-1875) reforça a importância de uma instituição escolar preparada e organizada. Sr. Trajano, um professor, é mencionado como um colaborador capacitado que "com uns dois anos de preparação, acredito que estaria capacitado para agir como evangelista e também instalar uma escola". Trajano, um homem, foi sondado, mas não tinha as prerrogativas de Mary Dascomb, o currículo, a preparação, a experiência, a disponibilidade.

Mas será que a Igreja Presbiteriana valorizava tanto assim as capacidades intelectuais de Mary Dascomb? Seria seu currículo o único e principal chamariz dos pastores e missionários da Missão no Brasil? Em carta escrita pelo Rev. George Chamberlain, de 13 de março de 1868, endereçada ao Rev. Dr. Irving, lemos: "Nós deveríamos ter três escolas imediatamente. Meu julgamento é que $600 \$$ cobririam todas as despesas de uma senhora solteira no Rio, pouco menos em São Paulo, menos ainda em Brotas".

Sustentar uma mulher solteira era mais barato que se responsabilizar pela manutenção de uma família inteira. Nomear mulheres para o trabalho de administrar e lecionar nas escolas americanas, como aconteceu com Dascomb, Kuhl, Kemper (em Campinas e Lavras) era uma economia para a Missão e a Igreja, além de garantir, inevitavelmente, mais tempo de dedicação dessas senhoritas às Escolas Americanas.

A primeira Escola Americana no Brasil começou a funcionar sob a direção de Mary Dascomb. O Annual Report de 1889 traz algumas informações sobre a missão no Brasil e também destaca o nome de Mary Dascomb como uma liderança neste país.

São Paulo: 300 milhas a oeste-sudoeste do Rio de Janeiro; principal cidade da província de mesmo nome; população, 27,000 (ver população); ocupado como uma estação de missão em 1863; trabalhadores missionários - Rev. Geo W. Chamberlain e mulher; H. M. Lane, Medical Doctor; Senhorita Ella Kuhl, Miss Mary P. Dascomb, senhorita PA Thomas, 9 professores, um leitor da Bíblia, e um vendedor de bíblias. Rev. D. McLaren, uma parte do ano.

Corytiba: cerca de 500 milhas a sudoeste do Rio de Janeiro; principal cidade da província do Paraná; trabalhadores missionários - GA Landes e esposa e dois vendedores de bíblia.

Neste país: James Theodore Houston, George W. Chamberlain, G. A. Landes, e suas esposas e Miss Mary P. Dascomb (Annual Report, 1889, p. 39).

Segundo Ferreira (1992, p. 211), a Escola Americana na capital paulista se notabilizou graças à atuação de Mary Dascomb e Elmira Kuhl, sua companheira de trabalho que chegou ao Brasil em 1874.

\section{CONCLUSÃO}

Mary Parker Dascomb, uma mulher pública, norte-americana, solteira, graduada e pósgraduada em sua área de atuação e que dedicou a maior parte da sua vida à educação brasileira. Sua prática docente, sua formação e pedagogia renovadoras, trazidas de sua pátria, difundidas aqui nas Escolas Americanas onde trabalhou, suas muitas leituras, interesses, constituíram-na uma educadora/ intelectual, capaz de intervir no debate educacional de sua época, de divulgar, ensinar, por meio de seus materiais de estudo e pesquisa e de sua atuação como diretora e professora da escola.

Mary, assim como outras viajantes, tinha uma grande capacidade de observação, que ultrapassa as diferentes circunstâncias singulares e as diferentes situações pessoais e políticas que 
enfrentam. Suas cartas, relatórios e escritos em geral, eram ricos em detalhes e forneciam inúmeros relatos e informações sobre sua vida, seu trabalho, sobre sua rede de pertencimento.

Nas "tramas" de sua história, separou-se de sua família para trabalhar no Brasil, em diferentes cidades. Conheceu outros mundos, apropriou-se de um projeto de educação e civilização e os fez circular. A missivista utilizava suas correspondências como instrumento de aproximação, de sociabilidade, buscada numa relação estreita de intimidade e respeito com seu interlocutor.

As cartas traduzidas, trocadas entre um homem e uma mulher, ambos norte-americanos, não são de amor. Uma mulher solteira que durante vinte e seis anos se correspondeu com um homem, sem que ao longo de 193 cartas - escritas em inglês arcaico e pessoalmente traduzidas ficasse evidente nenhuma relação afetiva/ sexual, apenas de trabalho.

O diferencial dos escritos de Mary Dascomb pode ser percebido em sua capacidade de aglutinar em torno de si uma rede de parentes e amigos, descritos e citados nas missivas, que recebiam benesses materiais e suporte afetivo e, em troca, lhe ofereciam o mesmo.

Apesar do período cronológico em questão ser caracterizado por mudanças políticas, sociais, econômicas, pedagógicas e por uma efervescência de ideias, em relação às mulheres as transformações não tiveram a mesma velocidade. A saída para uma relação de dominação construída histórica e culturalmente - dependeria, em grande parte, das próprias mulheres. E Mary não buscava conquistar um lugar de destaque, apesar de já o ocupar, de certa forma, uma vez que escapou de sua missão maternal e de seu lugar no lar, com um possível casamento, podendo dedicar-se livremente à sua profissão.

Sua atuação e sua experiência como mulher pioneira da missão presbiteriana no Brasil e da educação no final do século XIX e início do século XX, ligada à sua prática pedagógica e seu repertório pedagógico norte-americano, nos falam das possibilidades daquele momento e nos ajudam a pensar a História.

\section{REFERÊNCIAS}

ANNUAL REPORT the Board of Missions of the General Assembly of the Presbiteryan Church in the United States of America. Philadelphia Published by the Board. New York, 1889.

BLACKFORD, A.L. Relatório A. L. Blackford de julho de 1867 a agosto de 1868 . Relatório manuscrito apresentado ao Presbitério do Rio de Janeiro. 1867-1875.

BOURDIEU, Pierre. A ilusão biográfica. In. AMADO, J.; FERREIRA, M. (Org.) Usos e abusos da história oral. Rio de Janeiro: Fundação Getúlio Vargas, 1996, p. 183-191.

FERREIRA, Julio Andrade. História da Igreja Presbiteriana do Brasil. São Paulo: Casa Editora Presbiteriana, 1992. v. I

GAY, Peter. O coração desvelado. São Paulo: Companhia das Letras, 1999.

MALATIAN, Teresa. Cartas: Narrador, registro e arquivo. In: PINSKY, Carla Bassanezi; LUCA, Tânia Regina de (Orgs). O Historiador e suas fontes. São Paulo: Contexto, 2009. 